\title{
Singular Factors behind the Growth of Innovation in Israel
}

\author{
By Raphael Bar-El*, Dafna Schwartz , David Bentolila
}

Israel is known as one of the leading countries in innovation, mostly in terms of Research and Development $(R \& D)$ activity. We describe the growth of innovation activity and focus on the question about the leading factors that explain the rapid growth of innovation activity. Against the theoretical background of the rule of comparative advantage, we find that the innovation trend in Israel was mostly stimulated by comparative disadvantages. The explanation of the growth of innovative activities is mostly attributed to the characteristics of the national innovation ecosystem, and to the ability to understand its functioning and to derive appropriate policy measures. Using the data of 127 countries as gathered in the Global Innovation Index (GII), we propose a model for the explanation of the relative growth of innovation in Israel, and support it through an in-depth survey of the main leaders of innovation in the last years, from the fields of academy, industry and government.

Keywords: Israel, Innovation, Ecosystem.

\section{Introduction}

The state of Israel is considered as one of the leading economies in innovation achievement. It is ranked 11 out of 127 economies by the Global Innovation Index (Dutta et al. 2018). However, this cannot be explained by the factors which are generally considered as strong contributors to innovation, as mostly explained by the "triple helix" concept, which was developed quite intensively by Etzkowitz (see for example Etzkowitz 2008) and empirically tested in a few cases (Jackson et al. 2018). Moreover, Israel has been subject since its establishment to a few problematic constraints that are generally considered as inhibitors of economic growth: a small and geographically isolated market, lack of natural resources, heavy security needs, massive immigration flows.

In this article, we focus on the influence of exogenous constraints upon the ability to achieve innovation advance, beyond the well know influences of the classic factors of the innovation ecosystem. We use the case of Israel to show that constraints that are generally considered as negative factors by economic growth theories, may have an inverse influence upon innovation development. We relate to three specific issues.

First, we relate to the constraint of a small market (about 600 thousand inhabitants at the establishment of the state in 1948, until about 9 million in 2019), which significantly imposes two important restrictions: the potential for

\footnotetext{
*Professor, Ben-Gurion University, Israel.

${ }^{\dagger}$ Professor, Interdisciplinary Center (IDC) Herzliya, Israel.

${ }^{\ddagger}$ Coordinator of Management Division, Zefat Academic College, Israel.
} 
market-oriented innovation and the potential for venture capital availability. The response to this constraint was a governmental program of venture capital, YOZMA, with a strong orientation towards overseas linkages.

Second, we consider the extent to which the main factors of the innovation ecosystem have been influenced by the specific conditions of the state of Israel, and analyze the impact upon the relative role played by each factor. Given the extremely strong changes in the Israeli society as a result of various waves of enormous immigration flows, we focus mainly on the factor of culture and its implication upon innovation potential. In parallel, we evaluate the relative role of other main factors of the innovation ecosystem, as compared with their role in global literature.

Third, we relate to the exogenous negative factors of scarcity of natural resources (land, water, energy) and of the heavy defense needs, and show their positive influence upon an increasing motivation for innovation.

\section{The Market Constraint, the Unavailability of Venture Capital and the Geographical Isolation: The Role of the YOZMA Program}

As a consequence of an extremely small market at the establishment of the state in 1948 (about 600 thousand inhabitants, and of continuous economic and security tensions), for several decades Israel's economy was heavily dominated by the public sector and trade was greatly restricted. Since the late 1980s, the government has actively created policies to unleash the potential of the private sector and increase the business interaction with global markets. This policy was accelerated when the mass of immigrants came from the former Soviet Union, many of them with technological background.

Although the country enjoyed a relatively high level of $R \& D$ activities at the time with both civilian, military and government $R \& D$ support programs that were in place, the overall conditions were not ripe for venture investments. One of the perceived missing components was the unavailability of venture capital, as a result of the too limited potential of investors and of consumers.

As a public response to this perceived supply-side market failure, the Israeli government has set up a special program named YOZMA (which means "initiative" in Hebrew) - an equity co-investment program to channel equity finance to capital constrained but high potential, young enterprises, with a heavy orientation towards collaboration with overseas investors. The program was led by the Office of the Chief Scientist (today the Israel Innovation Authority), a central government agency responsible for fostering innovation in various industries. This led to the successful creation of the Venture Capital (VC) industry, which took place during the years of 1993 to 2000.

The Israeli Innovation Authority (at the time under the name of "Chief Scientist") allocated for that purpose $\$ 100$ million. Under the YOZMA program, $10 \mathrm{VC}$ funds were formed. Each of these funds was a privategovernment partnership of which the government's share was a maximum of $40 \%$ and the private investors' share $60 \%$. The private sector, according to 
YOZMA program, should be composed of partnership of leading Israeli financial institutions with leading foreign venture investors that have experience with startups (Schwartz 2009).

A major attraction of the YOZMA program was the private investors' option to buy out the government's share at a pre-determined price over a period of five years.

Thus the YOZMA program did not simply supply risk sharing to investors, it also provided an upside incentive - that private investors could leverage their profits through acquisition of the government shares. In addition, YOZMA was allowed to invest a certain portion of its capital directly in start-ups.

This program added the missing component to the ecosystem: risk capital as well as experienced private sector entities with local and global experience. These experienced investors provided "smart money" - beyond just funding: guidance on how to manage the startup, how to grow it, and how to market products to the world. While Israel had a long history of developing new technologies, the Israeli entrepreneurs lacked this kind of mentorship and the $\mathrm{VC}$ assisted in this area.

The YOZMA program immediately proved to be extremely successful and by 1999 , Israel ranked second only to the United States in invested privateequity capital as a share of GDP (Wikipedia).

Yin (2017) considers it as "the most successful and original program in Israel's relatively long history of innovation policy". The share of the venture capital of GDP in Israel is like in the United States, is representing more than $0.35 \%$ of GDP. While in the other OECD countries the venture capital constitutes, a very small percentage of GDP, often less than $0.05 \%$ (OECD 2017: 124)

Under the YOZMA program ten VC funds were formed and fifteen direct investments were made by YOZMA itself, and major international venture investors were attracted from all around the world: the USA, Germany, Japan, Netherlands, and Singapore (see Table 1).

Nine of the ten funds exercised their option and bought out the government's share. Nine out of the fifteen investments (made by YOZMA directly) enjoyed successful exits, either through Initial Public Offerings (IPOs) or through acquisition.

The YOZMA program was the catalyst for the development of the VC industry in Israel and for the development of the start-up sector as shown in the following figures. Prior to 1993, there was only one venture capital fund operating in Israel. In 2009, there were about 80 venture capital funds (IVC Research Center).

The capital raised by the VC funds grew from $\$ 40 \mathrm{M}$ in 1991 to $200 \mathrm{mil} \$$ in 1993, and reached a peak of 2.7 billion dollars in year 2000. In the last two decades, the average amount of capital raised by Israeli VC funds fluctuated around an average of 750 million dollars a year, including years of world financial crisis, as can be seen in Figure 1 (IVC online). 
Table 1. The YOZMA Funds

\begin{tabular}{|l|c|c|}
\hline Fund & International Investors & Country Origin \\
\hline Eurofund & Daimler-Benz, DEG (Germany) & Germany \\
\hline Gemini & Advent (USA) & USA \\
\hline Inventech & Van Leer Group (NL) & Netherlands \\
\hline JPV & Oxton (US/Far East) & USA \\
\hline Medica & MVP (USA) & USA \\
\hline Nitzanim-Concord & AVX, Kyocera (Japan) & Japan \\
\hline Polaris (Pitango) & CMS (USA) & USA \\
\hline Star & TVM (Germany) \& Singapore Tech & Germany \\
\hline Vertex & Vertex International Funds (Singapore) & USA, Singapore \\
\hline Walden & Walden (US) & USA \\
\hline $\begin{array}{l}\text { YOZMA - Direct } \\
\text { Investments }\end{array}$ & None & Israel Government \\
\hline
\end{tabular}

Source: Erlich (2013). Available at https://www.slideshare.net/AlanLung/th-erlich.

Figure 1. Capital Raised by Israeli VC Funds by Year (Billion Dollars)

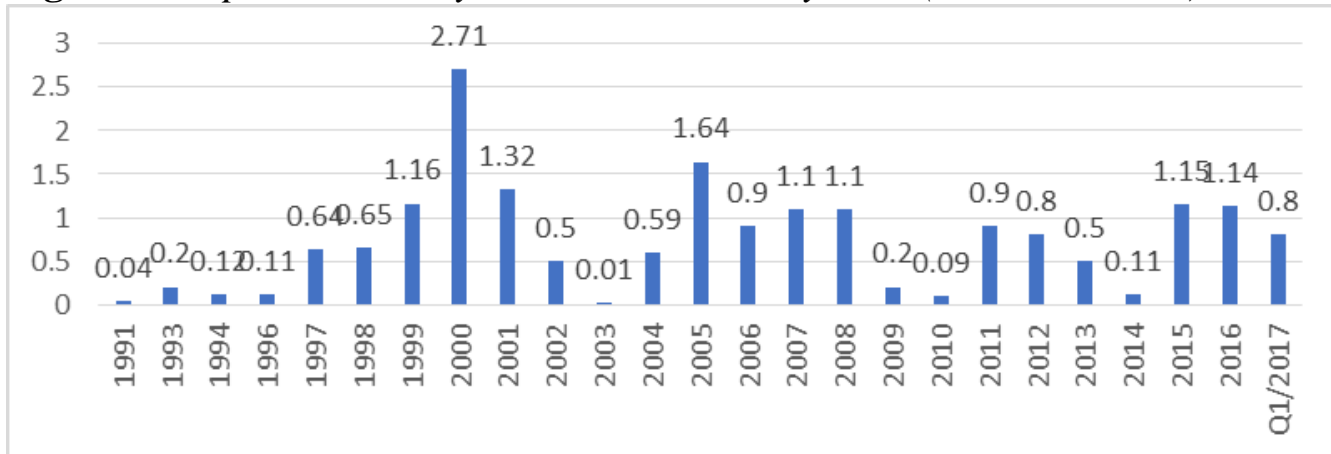

Source: IVC Research Center (Various Years).

The creation of the VC industry supported the establishment and the development of start-ups in Israel (Avnimelech and Schwartz 2008). From 51 before the YOZMA program, it grew constantly until reaching a peak of about 600 at the end of the century, as shown in the Figure 2. The creation of new start-ups stabilized around an average of about 500 every year in the following years and until present.

Figure 2. Number of Start-Ups Created in the Years After the YOZMA Program Was Established

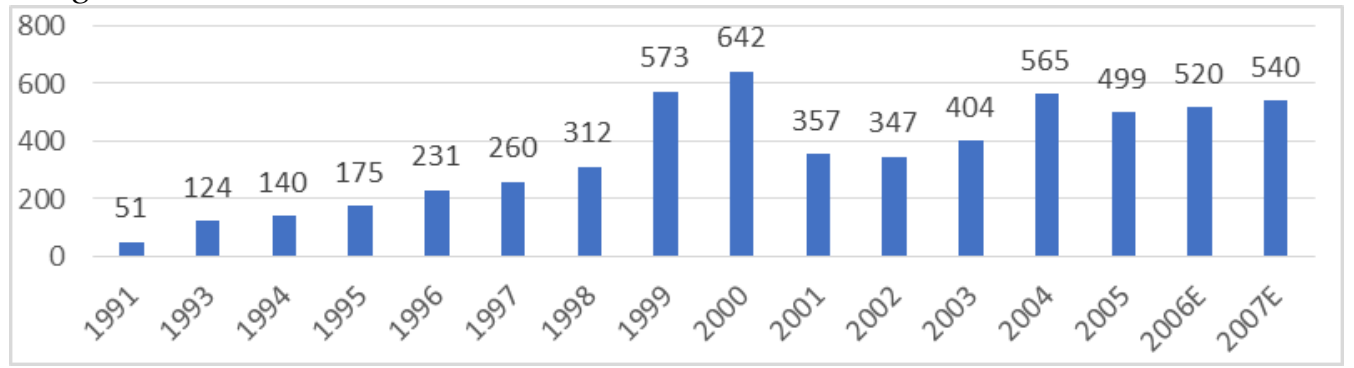

Source: IVC Research Center (2010) . 
Parallelly, the capital that was raised by the high-tech companies, most of them start-ups, from the VC investors rose dramatically, from less than $\$ 50 \mathrm{M}$ in 1991 to an annual average of \$1.6 billion during the period 1999-2007 (see Figure 3). After the global financial crisis, this amount has been constantly growing, reaching an average of about 5 billion dollars a year.

Figure 3. Capital Raised by Israeli High Tech Companies by Year (Billion Dollars)

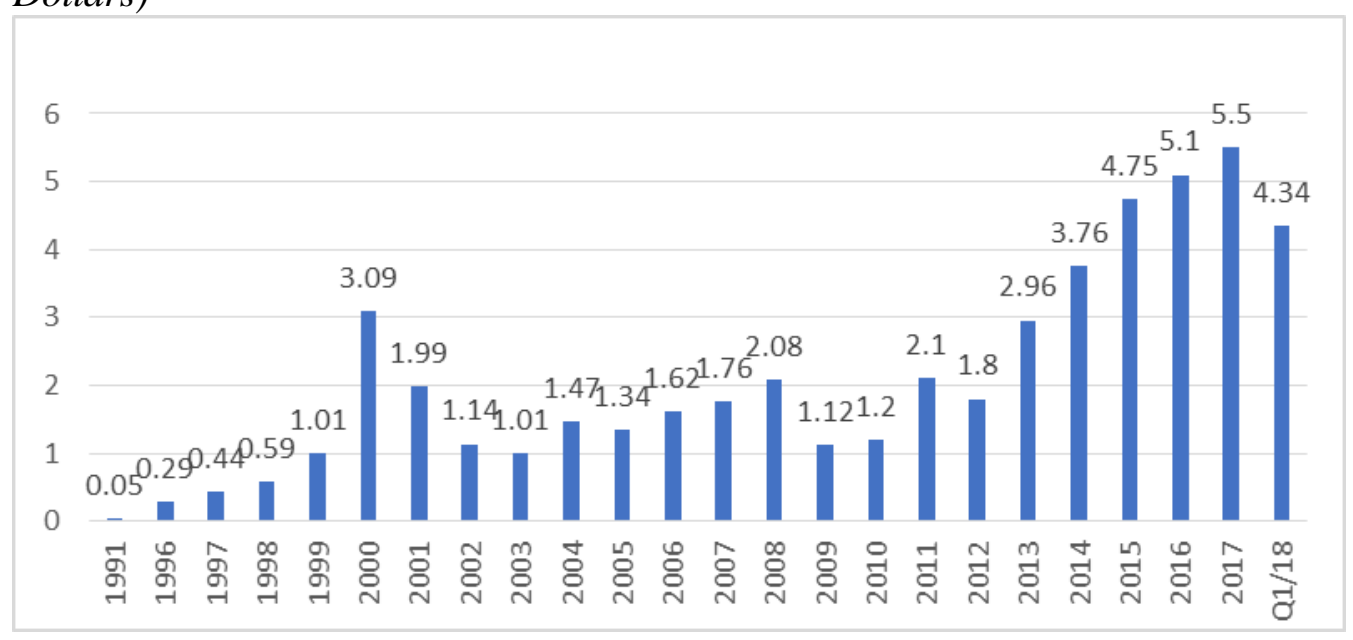

Source: IVC Research Center.

Even though the venture capital industry in Israel is very active, the role of the Innovation authority is still important. From 2014-2016, approximately $14 \%$ of start-up companies received a grant for R\&D activity from the Innovation Authority. 1115 projects of 650 companies were supported by the Authority in 2016. A total of 493 million NIS was granted. (Israel Innovation Authority 2019).

Below is a snapshot of the fluctuations during recent years (Kirshberg and Enselman 2018):

- In the years 2011-2016, 4,029 start-up companies were opened in Israel. 1,509 of them (37\%) were closed or delayed until 2016.

- In the years 2014-2016 there was an average annual decrease of $29 \%$ in the balance of openness and closing of start-up companies. This follows an average annual increase of 12\% in the years 2011-2013.

- Total revenue of start-up companies in 2016 amounted to NIS 6 billion ( $\$ 1.7$ billion), an increase of $2 \%$ compared with 2015.

- In 2016 the amount of employees were approximately 27,500 employee jobs in start-up companies, up 7\% compared to 2015.

- $64 \%$ of employee jobs are concentrated in software-based companies (applications for industries and businesses, medical information, Internet, mobile phone applications, security, e-commerce, and advertising).

Monthly wages per employee job (Kirshberg and Enselman 2018): 
- The average monthly wage per employee post in start-up companies in the year 2016 was NIS 13,800 (about \$3,680), an increase of 6\% compared to 2015 , and 1.5 times the average monthly wage for a wage job in the entire economy -NIS 9,200(\$2,453).

- In companies with a maximum of ten employee jobs, the average monthly wage per employee post in 2016 was NIS 12,300(\$3,280), and in companies with 21-21 employee jobs, the average monthly wage per employee post was NIS 20,500(\$5,467). In companies with more than 50 employee jobs, the average monthly wage is NIS $21,100(\$ 5,627)$, 2.3 times the average monthly wage in the economy.

Geographic distribution:

- In 2016, there were 1,836 companies in the Tel Aviv District, 268 companies opened and 159 closed.

- Most of the activity of start-up companies in Israel is concentrated in the Tel Aviv and Central Districts. 72\% of start-up companies and 78\% of employee jobs are concentrated in these districts.

- In the Tel Aviv District, the average monthly wage per employee post was the highest (NIS 14.6 thousand), and in the Jerusalem District and the South, the average monthly wage per employee post was lower (NIS 11,700 and NIS 11.2 thousand, respectively).

\section{Funding}

In the group of start-up companies, there was a continuation of the positive and consistent trend that began with the end of the global financial crisis. The large scope of funds raised by high-tech companies had a significant influence on this result. According to the IVC Research Center, approximately USD 4.8 billion flowed into the companies' cash reserves during 2016-2017, a figure that constitutes a new Israeli yearly record. This is while in the United States, venture capital investment actually declined for the first time after five consecutive years of growth.

Furthermore, the financing rounds themselves were larger than normal: the average round stood at approximately USD 7.2 million, some 20 percent more than the average between 2011-2016.

Quoting the director of the Authority of Innovation Aharon Aharon: "Israel is a technological innovation power, especially in the field of ICT (Information and Communication Technology). Technological Innovation is the key to economic prosperity, however the financial potential of Israeli innovation has yet to be fully realized... The Innovation Authority has formulated a strategy for preserving international competitive positioning and for increasing the economic-social yield from Israel's prospering technological innovation." 


\section{Factors of the Innovation Ecosystem}

Although a few basic factors may be generally identified as actors in the innovation ecosystem, their relative importance and role are not necessarily similar in each country. The specific conditions of the state of Israel could potentially inhibit an optimal functioning of some factors, leading to a decreased ability of innovation. The economic and social tensions resulting from the difficult conditions at the establishment of the state, the difficulties of integration between very different immigrants from European, Asian and African countries, constitute a problematic challenge for economic development and for innovation advancement.

An evaluation of the relative importance of major factors of the innovation ecosystem was made on the basis of in-depth interviews with 25 major leaders of the Israeli innovation ecosystem, and compared with the importance of such factors in the world as reflected by global literature (Turbiner et al. 2016). The Israeli leaders were selected from the three sectors of the triple-helix: government high level leaders of innovation (including most Chief Scientists), academic leaders in the field of innovation, and industrial leaders of major innovative firms. All interviewees had a deep involvement in the Israeli ecosystem, or/and were actually responsible for its practical implementation.

Five major factors were identified and their relative importance was quantified on a scale of 1 to 3 . We present the results by order of importance, as ranked by the leaders (Turbiner et al. 2016).

\section{Culture- Rank 1:}

The factor which was ranked at the highest level by far in Israel is culture, much before all other important factors. Culture is certainly recognized in world literature as an important contributor to innovation (Saxenian 1996, Frenkel et al. 2011, Wadhwa 2013, Dashti et al. 2008, Feldman 2014). Cultural values such as tolerance of risk and failure, individualism, low power distance and lack of formality were found to have a positive impact on the emergence of innovation and also to explain the difference in the level of innovation between countries. Similarly, a tendency towards networking, pluralism, cultural openness, spirit of authenticity, engagement and common purpose were also found to be elements that explain the power of certain innovation ecologies and firms over others.

Another factor is the mass immigration along a few decades from a wide variety of continents and cultures. Besides the frictions that result from such mix of cultures, on the long run this has contributed to some extent to an increasing tolerance level.

Despite the features of the Israeli population as stated above, those specific characteristics have probably most heavily contributed to innovation. In their book, Start-up Nation, Senor and Singer (2009) describe Israeli culture as being devoid of hierarchies and formality, a culture that includes a willingness to work hard, dedication, mutual responsibility, willingness to take risks and a 
unique approach to failure. According to the unique attitude towards failure found in Israel, it was found that Israeli culture is not averse to situations marked by uncertainty. In this context, a large number of the interviewees noted the contribution of military service in Israel as a factor that shapes and influences the perception of risk and ability to maneuver in conditions of uncertainty. It combines original thought with initiative and strong performance that later translate into a culture that supports innovation in the business arena. Other cultural aspects noted in the interviews as supporting innovation include the tendency to challenge conventions, thinking outside the box, strong improvisational skills and a strong tendency to network.

\section{Information and Communication Technologies (ICTs)- Rank 2:}

It is described in the literature as having a substantial impact on increasing efficiency and productivity of innovation activities. In general, a strong correlation was found between the degree of development of ICT infrastructure and the country's level of innovation. As a result, many countries attribute a great deal of value to the development of technological infrastructure that supports innovation and to increasing its use. A developed ICT infrastructure significantly reduces the impact of geographic distance on the emergence of innovation and serves as a catalyst for its formation by reducing the costs associated with innovation activities and raising capital, making global platforms of knowledge and information accessible, and enhancing the ability to share, process, discuss and distribute information (Rogers 2003, World Economic Forum 2013, Chemmanur and Fulghieri 2014). The findings of the interviews of the main Israeli leaders are in line with those of literature.

\section{Academia- Rank 3:}

Research literature shows that Academia and Research Institutes have a marked impact on the emergence of innovation, which can be seen in the creation of two critical components of innovation - human capital and knowledge. These inputs form the foundation of applied research, product and process innovation in industry (Bercovitz and Feldmann 2006, Etzkowitz and Leydesdorff 2000).

The field study in Israel shows that Academia has a quite moderate influence on the advance of innovation. However, it should be noted that a low influence was attributed to Academia by leaders of the public and the private sector, while academic leaders evaluated a quite higher influence.

\section{Venture Funding- Rank 4:}

The importance of the financing bodies in the emergence of innovation can be seen, firstly and foremostly, through their being suppliers of capital and virtually the only source of financing for entrepreneurial and innovation activity which entails great risk. A lack of venture financing entities has been 
found to be a barrier to innovation activity and economic growth (King and Levine 1993, World Economic Forum 2013). Furthermore, the contribution of these entities to the emergence of innovation is also manifest in other aspects that improve the odds of success for innovative ventures such as monitoring of venture development, assistance in building quality management teams, mentoring based on know-how and professional experience, connections to local and global networks, providing a strong reputation to the funded companies, and more (Chemmanur et al. 2011).

In Israel, as shown previously, the establishment of the YOZMA program was a key factor in the ignition of the innovation process. However, the importance of the access to venture capital was indicated by the leaders in the field study only as moderate, differently from the extremely high importance attributed to this factor in the world. This can be explained by the fact that the success of the YOZMA project has led to a continuous privatization of the venture capital funds, making them more accessible on a free market basis, and therefore regarded as less critical to the advance of innovation.

\section{Government- Rank 5:}

The research literature shows that Government and Public Agencies play a central role in leading innovation and that they are actually key and highly influential innovation agents in the innovation ecosystem. The contribution of these factors to the emergence of national innovation is described as being broader and more comprehensive than addressing market failures and includes a variety of interventions in different contexts and time intervals (Mazzucato 2011). The means for promoting innovation that are available to the Government and Public Agencies include both direct support of industrial $\mathrm{R} \& \mathrm{D}$, deployment of physical infrastructures, financing of basic research, education and development of human resources as well as means that can stimulate innovation processes, which are not based on conventional expansionary fiscal policy such as tax incentives, enacting laws, regulations and agreements (for example, tax policy, copyright protection, international cooperation agreements, immigration policy, etc.).

The Israeli government has generally received international recognition for its economic policy, which relates to growth and innovation challenges. Furthermore, a positive correlation was found between government programs and actions in the field of innovation and various aspects of innovation, as seen in the Israeli economy. Two salient examples in this regard are the Technological Incubators Program and the YOZMA Program, which were successfully implemented by the government at the beginning of the 1990s (Schwartz et al. 2012, Frenkel et al. 2011, Schwartz and Bar-El 2007, Avnimelech et al. 2008).

Despite the evidence in the research literature regarding the importance of the contribution of Government and Public Agencies to the emergence of national innovation, the findings of the interviews show that currently, after the achievement of a substantive advance of the innovation ecosystem and an 
increasing access to venture capital, on average, the interviewees in this study did not perceive the contribution of government as very strong. This finding is especially interesting given the fact that half of the interviewees who belong to the industrial sector received support from the government to finance their innovative activity. Again, we may conclude that Government was an extremely important player in the ignition of the innovation process in Israel, but the progress and the continuous privatization of the innovation process made the contribution of government as less critical.

\section{Specific Exogenous Factors}

The functioning of the national innovation ecosystem may be influenced by various exogenous factors, which are specific to each country or region. In the Israeli case, we identify three major factors that generally constitute an impediment to economic growth: the scarcity of land and water, the lack of energy sources and the heavy defense needs. Surprisingly, those three elements played a major role in the advance of innovation in Israel.

The scarcity of land and of water was a major constraint to the Jewish aspiration after the Holocaust for the establishment of a state and to the need of a quite massive migration. However, such scarcity led to the need for an extremely efficient use of land and water. Consequently, many efforts were done in the development of agricultural technology, of advanced production processes, of new agricultural products. The scarcity of water was a major stimulator in the research and development of water desalination and of the treatment of used water. It was also a major stimulator in the invention of new irrigation methods, mostly including the invention of drip irrigation.

The lack of energy resources in a country surrounded by countries with high reserves of oil led to the continuous search of energy resources (rewarded by the discovery of gas in the last few years), and to the major efforts in the use of solar energy.

The defense needs as a result of military tensions with a multitude of surrounding enemy countries, together with unstable political relations with other countries led to the investments of heavy efforts in the development of local military instruments, first focused on automatic arms and ammunitions, but later shifting to the development of heavy defense devices, usually with no economic viability in a small country. This includes the development of a tank that responds to specific Israeli needs, the Arrow project, and more. The creation of a special military airplane ("Lavi") was even initiated but failed after a few years.

\section{Conclusion}

Israel would not be expected to be a leading country in the process of innovation, following the quite accepted theories that explain the advance of 
innovation. It is quite a small country with no local significant market, it is geographically isolated, its infrastructures and its human capital are good but not at the level of many developed countries. Still it is ranked today as one of the leading countries of the world in innovation. Innovative activity covers many sectors, the numbers of new start-ups are high, external investments are impressive.

A few main factors probably are at the root of such results. First, an important factor in the creation of innovation was rapidly identified by Israeli policy: the critical contribution of venture capital. The establishment of the YOZMA program, with a quite high allocation of venture capital funds and the collaboration with the experienced local and global private sectors, was a major element in the ignition of the venture capital industry and of the innovation process.

Second, the special cultural or human characteristics of the Israeli population played an important role: the extreme diversity of the population (reinforced by the mass immigration coming from the ex-Soviet Union), the non-conformist behavior, the rejection of authority, all those characteristics that are generally considered as negative to economic success, played a positive role in the advance of innovation.

Third, surprisingly enough, exogenous factors that mostly impose heavy constraints on macro-economic development, made a major contribution to the stimulation of new fields of innovation in Israel: the lack of natural resources, the problematic political and defense situation made the need for innovative responses critical and led to innovation in fields generally dominated by big economies.

Fourth, innovation ecosystems are dynamic and should be adapted along the process of innovation. The role of the government in the provision of infrastructures and venture capital is vital at the first phases, leading to a fading out to private venture capital, and to the increasing relevance of cultural aspects of the local population.

\section{References}

Avnimelech G, Schwartz D, Teubal M (2008) Entrepreneurial High-Tech cluster development. In C Karlsson (ed) Handbook of Research on Innovation and Clusters: Cases and Policies, 124-148. UK: Edward Elgar.

Bercovitz J, Feldmann M (2006) Entpreprenerial universities and technology transfer: A conceptual framework for understanding knowledge-based economic development. Journal of Technology Transfer 31(1): 175-188.

Chemmanur TJ, Krishnan K, Nandy DK (2011) How does venture capital financing improve efficiency in private firms? A look beneath the surface. The Review of Financial Studies 24(12): 4038-4090.

Chemmanur TJ, Fulghieri P (2014) Entrepreneurial finance and innovation: An introduction and agenda for future research. The Review of Financial Studies 27(1): 1-19. 
Y Dashti, D Schwartz, Pines AM (2008) High technology entrepreneurs, their social networks and success in global markets: The case of Israelis in the US market. Current Topics in Management (13): 131-144.

Dutta S, Lanvin B, Wunsch-Vincent S (2018) Global Innovation Index 2018- Energizing the World with Innovation. Cornell SC Johnston College of Business, INSEAD, WIPO.

Erlich Y (2013) The Yozma Program - Success Factors and Policy. Available at https:// www.slideshare.net/AlanLung/th-erlich.

Etzkowitz H, Leydesdorff L (2000) The dynamics of innovation: from National Systems and "Mode 2" to a TripleHelix of university-industry-government relations. Research Policy 29(2): 109-123.

Etzkowitz H (2008) The Triple Helix: University-Industry-Government in Action. Routledge, London.

Feldman MP (2014) The character of innovative places: entrepreneurial strategy, economic development, and prosperity. Small Business Economics 43(1): 9-20.

Frenkel A, Meital S, Leck E, Getz D, Segal V (2011) Towards Mapping National Innovation Ecosystems, Israel's Innovation Ecosystems. Haifa: Samuel Neeman Institute.

Israel Innovation Authority (2019) Innovation in Israel Overview, 2018-2019, Ministry of Economy and Industry.

IVC Research Center, IVC-online website (various years). Available at https://www.ivconline.com/.

Jackson P, Kiani Mavi R, Suseno Y, Standing C (2018) University-industry collaboration within the triple helix of innovation: The importance of mutuality. Science and Public Policy 45(4): 553-564.

King RG, Levine R (1993) Finance, entrepreneurship, and growth. Journal of Monetary Economics 32(3): 513-542.

Kirschberg E, Enselman T (2018) Business-Economic Statistics Department, Israel Innovation Authority -Innovation in Israel overview 2017, Media Release Jerusalem 21 May 2018.

Mazzucato M (2011) The Entrepreneurial State. London: Demos.

OECD (2017) Venture Capital Investments, Entrepreneurship at a Glance 2017. Paris: OECD Publishing. Available at: https://doi.org/10.1787/entrepreneur_aag-2017-25en.

Rogers E (2003) The Diffusion of Innovations (5th ed.). New York: The Free Press.

Saxenian A (1996) Regional Advantage: Culture and Competition in Silicon Valley and Route 128. USA: Harvard University Press.

Schwartz D, Bar-El R (2007) Venture investments in Israel - A regional perspective. European Planning Studies 15(5): 623-644.

Schwartz D (2009) venture capital and business development in Israel. In J Osmond (ed) Regional Economies in a Globalising, 76-79. World Institute of Welsh Affairs, ISBN: 9781904773450.

Schwartz D, Avnimelech G, Bar-El R (2012) The Location of Knowledge Economy and High-Tech in Israel. In A Frenkel, P Nijkamp, P McCann (eds) Societies in Motion: Innovation, Migration and Regional Transformation, 114-138. Cheltenham, UK: Edward Elgar.

Senor D, Singer S (2009) Start-Up Nation. New York: Grand Centeral Publishing.

Turbiner Y, Schwartz D, Bar-El R (2016) Innovation ecosystems: practice vs. prevailing perceptions. International Journal of Innovation and Scientific Research 22(2): 444455. 
Yin D (2017) What Makes Israel's Innovation Ecosystem So Successful, Forbes. Available at: https://bit.ly/2Wgv2Jf.

Wadhwa V (2013) Silicon Valley Can't Be Copied. MIT Technology Review. Available at: https://bit.ly/1sxOLNr.

World Economic Forum. (2013). The Global Competitiveness Report 2013-2014. Geneva: World Economic Forum. 
